\title{
Uterus Didelfis Olgusunda Dikaviter İkiz Gebelik
}

\author{
Dicavitary Twin Pregnancy in Didelphys Uterus \\ Necip Cihangir YILANLIOĞLU ${ }^{1}$, Koray ÖZBAY ${ }^{1}$, Resul ARISOY ${ }^{1}$, Semra KAHRAMAN ${ }^{2}$
}

1. Memorial Şişli Hastanesi, Kadın Hastalıkları ve Doğum Kliniği, İstanbul, Türkiye

2. Memorial Şişli Hastanesi, Yardımcı Üreme Teknolojileri ve Genetik Merkezi, İstanbul, Türkiye

\section{$\ddot{O Z Z T}$}

Amaç: Uterus didelfis anomalisi olan infertil hastada IVF tedavisi ile elde edilen dikaviter ikiz gebelik olgusunu literatür bilgileri eşliğinde sunmak.

Olgu: 29 yaşında primer infertil hasta gebelik elde etme arzusu ile hastanemizin tüp bebek ünitesi'ne başvurduktan sonra daha önce varlığ bildirilmis olan "uterus didelfis" anomalisi ultrasonografik değerlendirme ve histerosalpingografi ile teyit edildi. Uterin anomali dıșında özgeçmișinde bir özellik bulunmamaktaydr. Daha öncesinde erkek faktörü nedeniyle uygulanan iki bașarislz in vitro fertilizasyon denemesi olan hastaya yapılan tedavide her bir kaviteye bir tane 5. gün embriyosu transfer edildi ve her iki embriyonun implante olmast neticesinde dikaviter ikiz gebelik geliști. Gebelik elde edildikten sonra takipleri hastanemizin kadın hastalıkları ve doğum kliniği tarafindan yapıld. Siddetli preeklampsi gelişmesi nedeniyle 35 hafta 4 günlük iken sezaryen-tek uterin insizyon ile ikiz bebekler doğurtuldu.

Sonuç: Uterus didelfis anomalisinde dikaviter ikiz gebelik olguları çok nadir olup, başarılı gebelik sonuçları için yakın takip önemlidir. Bu olguların doğumu veya sezeryanı özellikli olup, deneyimli kliniklerde yapılmalıdır.

Anahtar Kelimeler: uterin anomali, didelfis, uterus, ikiz gebelik

\section{ABSTRACT}

Objective: The aim of this study is to present a case of a dicavitary twin pregnancy delivered at the 36th week of pregnancy by cesarean section in a woman with didelphys uterus where the pregnancy was achieved with in vitro fertilization technique, in the light of the literature.

Case: A 29-year-old primary infertile patient admitted to our hospital's IVF unit with the desire to become pregnant, diagnosed with uterus didelphys anomaly. There was no problem in her medical history other than this uterine anomaly. She had two unsuccesful in vitro fertilization attempts previously performed due to a male factor. Dicavitary twin pregnancy was obtained with the aid of in vitro fertilization and embryo transfer to both uteruses. Pregnancy follow-up was performed by the gynecology and obstetrics clinic of our hospital. Twins were delivered by cesarean section-single uterine incision at 35 weeks and 4 days as necessitated by severe preeclampsia.

Conclusion: Dicavitary twin pregnancy cases are very rare in uterine didelphys anomaly and close follow-up is important for successful pregnancy outcomes. The birth or the cesarean section of this condition are specified cases and should be done in experienced clinics.

Keywords: uterine anomaly, didelphys, uterus, twin pregnancy

\section{İletişim}

Sorumlu Yazar: Koray ÖZBAY

Adres: Memorial Şişli Hastanesi, Kadın Hastalıkları ve Doğum Kliniği, İstanbul, Türkiye

Tel: +90 (539) 4737958

E-Posta: ozbaykoray@gmail.com

Makale Geliş: 04.09.2019

Makale Kabul: 26.10.2019

DOI: http://dx.doi.org/10.16948/zktipb.615521

\section{GİRIŞ}

MKA (Müllerian Kanal Anomalileri) anormal embriyolojik gelişim sürecinden kaynaklı kadın genital sisteminin konjenital defektleridir. Bu anomaliler gelişim, füzyon, kanalizasyon veya reabsorpsiyon'da oluşan aksamalardan kaynaklı olabilmekte ve gebeliğin 6-22. haftaları arasında oluşmaktadırlar (1). UD (Uterus Didelfis) genel popülasyona oranla infertil kadınlarda prevalansı daha yüksek olarak bildirilen bir müllerian kanal füzyon anomalisidir. Müllerian kanalın füzyonunun gerçekleşmemesi neticesinde iki ayrı uterus ve iki ayrı serviksle karakterizedir. Bazen longitudinal veya transvers bir vajinal septum da eşlik edebilmektedir (2). Uterin malformasyon sıklığı genel popülasyonda \%7'dir. MKA içinde \%55 ile uterin septum en sı izlenirken, UD'in sıklı̆g 1 yaklaşık olarak \%5'tir ve prevalans1 1/1000-1/30.000 arasında bildirilmektedir $(2,3)$. Uterin anomaliler preterm doğum, gebeliğin hipertansif hastalıkları, sezaryen doğum, prezantasyon anomalisi, plasental dekolman, tekrarlayan gebelik kayıpları ve intrauterin büyüme geriliği gibi durumlar ve kötü gebelik sonuçları ile ilişkilidirler $(1,4,5)$. Kötü gebelik sonuçları daha çok majör füzyon defektleri olarak siniflandirılan unikornuat, bikornuat ve didelfis uteruslarla ilişkilidir (4). UD olgularında bikornuat ve uterin septum olgularına kıyasla terme ulaşan gebelik oranları daha yüksektir, viable gebelik oran1 \%60-70'tir (1). Literatürde UD olgularında tekil gebelik ile ilgili bilgi nispeten daha çok iken çok daha nadir görülen UD'te dikaviter ikiz gebelik ile ilgili bilgi yetersizdir (2).

Uterus didelfis anomalisi olan olguda; IVF ile elde edilen dikaviter ikiz gebeliğin yönetimini tartışmayı amaçladık.

\section{OLGU}

28 yaşında ve 2,5 yıllık evli olan primer infertil hasta hastanemizin tüp bebek kliniğine başvurdu, daha önceden sol uterin kaviteye uygulanan 2 IVFET (in vitro fertilizasyon-embriyo transferi) başar1sızlığı bulunmakta idi. İnfertilitede ana sebep olarak oligo-asteno-teratozoospermi saptand1.

Sağ kaviteye iki kez uygulanan dondurulmuş embriyo transferinde olumlu netice alınamadı, kliniğimizdeki üçüncü dondurulmuş embriyo transferinde sağ ve sol kaviteye birer 5. gün embriyosu transfer edildi. IVF-ET sonrası dikaviter ikiz gebelik elde edildi. Gebelik takiplerine kadın hastalıkları ve doğum kliniğinde devam edildi. Ultrasonografide vital dikaviter ikiz gebelik net olarak izlendi (Re$\operatorname{sim} 1)$. 


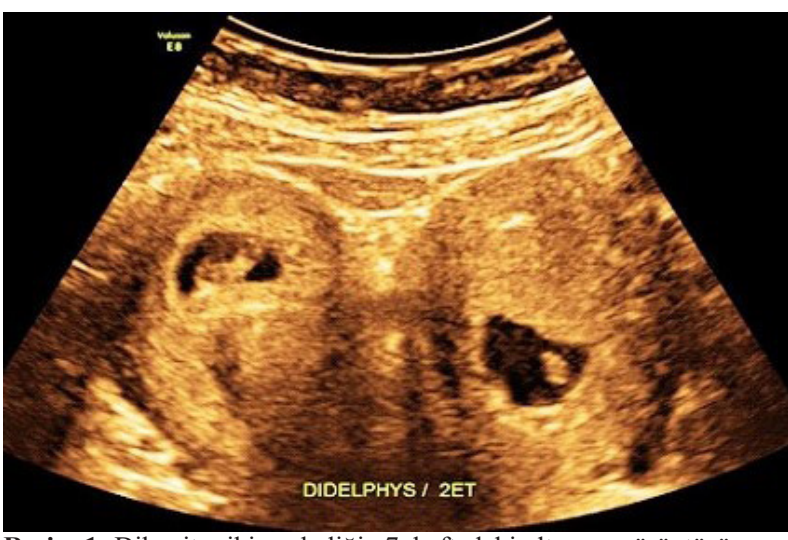

Resim 1: Dikaviter ikiz gebeliğin 7. haftadaki ultrason görüntüsü.

Gebelik takipleri 2 haftalık aralıklarla yapıldı. 12. haftada yapilan ultrasonografik muayenede plasenta anterior yerleşimli tespit edildi, yapılan uterin arter Doppler değerlendirmesinde sağ ve sol uterin arter Pİ (pulsatilite indeksi) değerleri sırasıyla 2,5 ve 2,7 olarak saptandı. Artmış uterin arter direnci saptanması üzerine asetil salisilik asit $150 \mathrm{mg} /$ gün başland1. 19. gebelik haftasında yapılan detaylı fetal anatomik değerlendirmede anomali bulgusu saptanmadi.

Gebeliğin 35. haftasına kadar hastanın genel durumu, biyokimya, hemogram ve vital takip bulguları normal seyretti. 35. gebelik haftasında kliniğimize baş ve sağ üst kadran ağrısı şikayeti ile başvuran hastanın kan basıncı 168/115 mmHg olarak saptand1. Aralıklı olarak yapılan kan basınc1 ölçümleri 160/110 mmHg'nın üstünde seyretti. Yapılan tetkiklerde trombosit değeri $92.000 / \mathrm{dL}$, AST:68 U/L, ALT:53 U/L, kreatinin 1mg/dl, olarak tespit edildi. Spot idrarda $2+$ proteinüri mevcut idi. Şiddetli preeklampsi tespit edilmesi nedeniyle hasta interne edildi; 4,5 gram yükleme dozunu takiben 24 saat süre ile 1.5 gram/saat dozunda $\mathrm{MgSO} 4$ tedavisi uygulandı. Yüksek tansiyon $(\geq 160 / 110)$ nedeniyle Nifedipin verildi. Tedaviyi takiben hastanın doğumu 35 hafta 4 günlük iken acil sezaryen ile gerçekleştirildi, 1 ve 5. dakika Apgar skorları 8-9 olan 2434 ve 2588 gram ağırlığındaki ikiz kız bebekler baș gelişi olarak doğurtuldu. Plasenta ağırlıkları sirasıyla 480 ve 580 gram olarak ölçüldü. $\mathrm{MgSO}_{4}$ tedavisi postpartum 24 saat devam edildi.

Resim 2: Sezaryen doğum sonrası didelfis uterus görünümü.

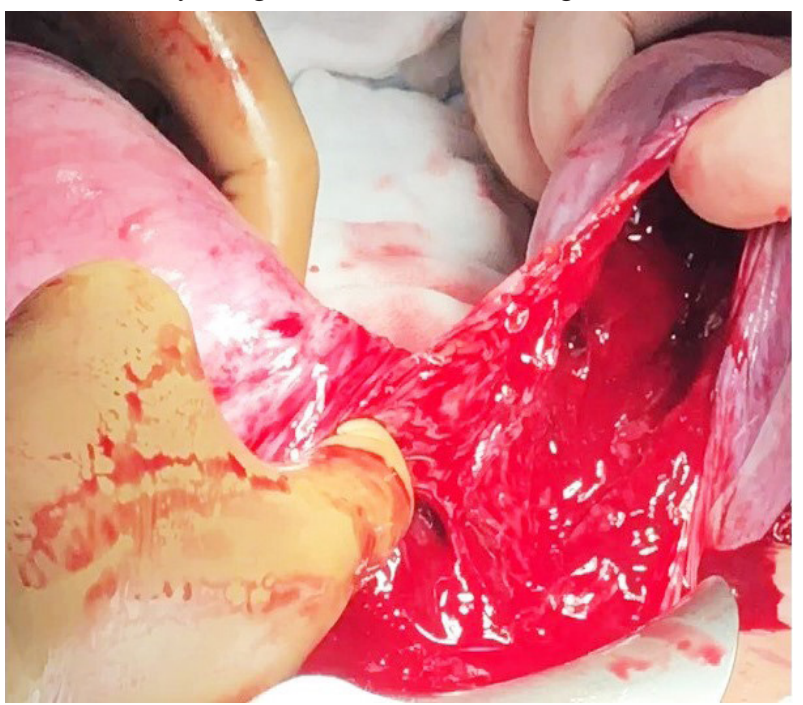

Ayrica sezaryen sırasında uterotomi iki uterus'un birleşim yerinin $1 \mathrm{~cm}$ inferior'undan yapılan tek bir insizyon ile uygulandı ve sütüre edildi (Re$\operatorname{sim} 2$, Resim 3), mesaneden rektuma uzanan "rekto-vezikal ligament” tespit edildi (Resim 4).

Resim 3: Her iki kaviteye de ulaşılabilen tek transvers uterotomi sütürasyonu.

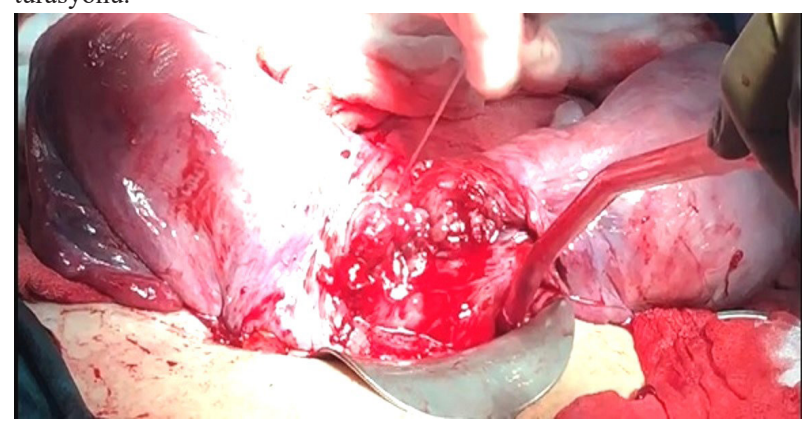

Resim 4: Rekto-vezikal ligament.

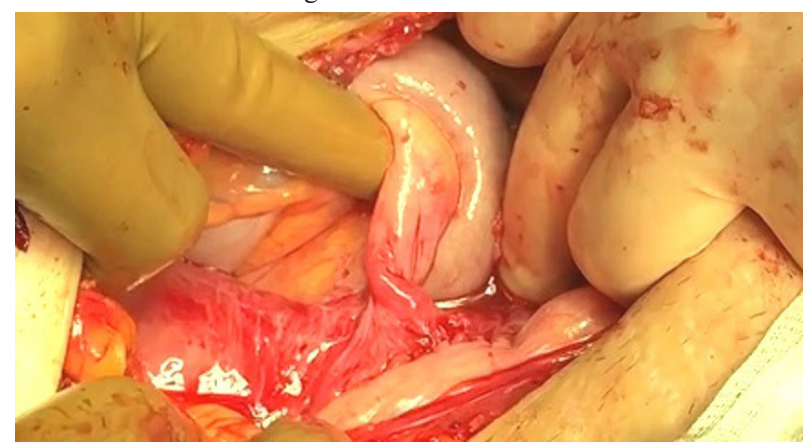

Postoperatif süreçte hasta stabil seyretti, doğum sonrası kan basınc1 değerleri 150/100 mmHg'nın altında ve postoperatif 2. gün AST-ALT değerleri sırasıyla 39 ve $37 \mathrm{U} / \mathrm{L}$, kreatinin $0.8 \mathrm{mg} /$ $\mathrm{dl}$, trombosit değeri $162.000 / \mathrm{dL}$ idi. Hasta postoperatif 3. günde taburcu edildi.

\section{TARTIŞMA}

UD olgularında dikaviter ikiz gebelik insidans1 1:1,000,000 olarak bildirilmektedir. Gebeliğin spontan veya ÜYT (üremeye yardımc1 teknikler) ile olduğuna yönelik bir rakam bulunmamaktadır. Literatürde UD olgularında dikaviter ikiz gebelik sonrası vajinal doğum bildirilen az sayıda yayın mevcuttur (2). UD anomalisi tek başına sezaryen endikasyonu değildir, doğum şeklinde ilk seçenek olarak vajinal doğum değerlendirilmelidir. Eğer vajinal septum çok kalın ve elastikiyeti az ise distosi riski nedeniyle sezaryen doğum düşünülmelidir (1). Normal doğumda küçük, rijit bir serviks ve muskuler yapısı iyi gelişmemiş bir uterus nedeniyle doğum uzayabilmektedir (6). Doğum sürecinde 5-66 gün aralık ile önce bir tarafin sonra da öbür taraftaki bebeğin doğumunun gerçekleştirilebileceği ve uteruslarda kontraksiyonların asenkron başlayabileceği veya seyredebileceği bildirilmiştir (7-9). Bunun sebebi olarak uterusların fonksiyonel anlamda birbirlerinden bağımsız olması, doğumu başlatan mekanizmanın sistemikten çok lokal bir fenomen olması düşünülmektedir.

Dikaviter ikiz gebelik, birbirinden bağımsız iki ayrı tekil gebelik olarak da değerlendirilebilir (8). Her iki bebeğin de vajinal yolla, her iki bebeğin 
sezaryen ile, ilk bebeğin sezaryen ikincisinin vajinal doğum veya tam tersi ilk bebeğin vajinal yol ikinci bebeğin sezaryen ile doğumunun gerçekleştirildiği dikaviter ikiz gebelikler literatürde mevcuttur $(2,7$, $8,10,11)$. Heinonen PK 21 y1llık bir süreçte tekil gebeliklerin izlendiği 26 olguluk serilerinde bir sezaryen gerekçesi olan makat prezantasyon oranını $\% 43$ olarak bildirmiștir (12). Kendi olgumuzda fetal prezantasyon her iki bebek için baş gelişi idi, dolayısyla sezaryen gerekçesi olarak malprezantasyon yoktu, doğum şeklini klinik durum belirledi. Literatürde uterin anomalilerde sıklığının arttı̆̆ preeklampsi olgumuzda da gelişti. Şiddetli preeklampsi gelişmesi sezaryen ile doğum kararı almamıza neden oldu.

MKA ve gebelik birlikteliği servikal yetmezlik açısından riskli olarak kabul edilmektedir ve ikiz gebeliklerde preterm doğum oranı tekil gebeliklere oranla daha yüksektir (sırasiyla $\% 1-2$ ve $\% 5$ 10) $(13,14)$. Önceki gebeliklerinde erken doğum hikayesi olan, $25 \mathrm{~mm}$ 'den k1sa serviks veya dilate serviks tespit edilen hastalar dişında kalan uterin anomalisi olan hasta grubuna serklaj önerilmemektedir (4). Erken doğumun önlenmesinde haftalık "hidroksiprogesteron kaproat" intramuskuler uygulamasının kullanılabileceği bildirilmiştir (5). Bizim olgumuzun klinik takiplerinde erken doğum riski açısından ek risk saptanmadi.

Literatürde, sezaryenlerde iki ayrı uterotomi uygulanması önerilmiştir (11). Fakat biz uterotomiyi devam eden tek bir insizyon şeklinde başarı ile uyguladik. İki ayrı uterotomi yerine iki uterus'un birleşim yerinin $1 \mathrm{~cm}$ inferior' undan yapılan tek bir insizyon ile iki kaviteye de ulaşılabileceğini bu olgu sunumu ile gösterdik. Yine UD olgularında mesaneden rektuma uzanan peritoneal bir bant tanımlanmıştır, "rekto-vezikal ligament" kendi olgumuzda da saptanmıştır, sezaryen ile doğumda bu ligament gözlenmelidir çünkü uterus posteriorunda rektum uterus'a daha yüksek bir seviyede adhere olarak izlenilebilir, bağırsak ve mesane yaralanması olmaması için dikkat sarfedilmelidir.

\section{SONUC}

Didelfis uteruslarda ikiz gebelik riskli gebelik kategorisindedir, bu nedenle bu anomalinin erken dönemde saptanması, fetal büyümenin yakın takibi, servikal uzunluk değerlendirilmesi çok önemlidir. Artmıș preterm doğum, gebeliğin hipertansif hastaliklar1 ve plasental dekolman riski nedeniyle antenatal takiplere özen gösterilmelidir. Uterus didelfis anomalisinde dikaviter ikiz gebelik olgularında başarılı gebelik sonuçları için yakın takip önemlidir. $\mathrm{Bu}$ olguların doğumu veya sezeryanı özellikli olup, beceri ve deneyim gerektirmektedir.

\section{KAYNAKLAR}

1. Rezai S, Bisram P, Lora Alcantara I, Upadhyay R, Lara C, Elmadjian M. Didelphys Uterus: A Case Report and Review of the Literature. Case Rep Obstet Gynecol. 2015;2015:865821.

2. Al Yaqoubi HN, Fatema N. Successful Vaginal Delivery of Naturally Conceived Dicavitary Twin in Didelphys Uterus: A Rare Reported Case. Case Rep Obstet Gynecol. 2017;2017:7279548.

3. Bhagavath B, Ellie G, Griffiths KM, Winter T, Alur-Gupta S, Richardson C, Lindheim SR. Uterine Malformations: An Update of Diagnosis, Management, and Outcomes. Obstet Gynecol Surv. 2017;72:377-392.

4. Khander A, Stern E, Gerber RS, Fox NS. The association between obstetrical history and preterm birth in women with uterine anomalies. J Matern Fetal Neonatal Med. 2018;31:25502554.

5. Ng KS, Ng BK, Lim PS, Shafiee MN, Abdul Karim AK, Omar $M H$. Use of hydroxyprogesterone caproate to prevent preterm labour in uterine didelphys: a case report. Horm Mol Biol Clin Investig. 2016;27:89-91.

6. Brown $O$, Mahedran D, Lieberman B. A twin pregnancy in a uterus didelphys. J Obstet Gynaecol. 1999;19:82-3.

7. Maki Y, Furukawa S, Sameshima H, Ikenoue T. Independent uterine contractions in simultaneous twin pregnancy in each horn of the uterus didelphys. J Obstet Gynaecol Res. 2014;40:836-9.

8. Nohara M, Nakayama M, Masamoto H, Nakazato K, Sakumoto $K$, Kanazawa K. Twin pregnancy in each half of a uterus didelphys with a delivery interval of 66 days. BJOG. 2003;110:331-2.

9. Tyagi A, Minocha B, Prateek S. Delayed delivery of second twin in uterus didelphys. Int J Gynaecol Obstet. 2001;73:259-60.

10. Ani EO, Ugwa EA, Taiye AB, Agbor IE, Suleiman IS. Simultaneous pregnancy in each uterine cavity of a double uterus in a young Nigerian multipara who presented with a retained second twin following an unsupervised preterm labor at home; Case report. Int J Surg Case Rep. 2018;42:224-226.

11. Kekkonen R, Nuutila M, Laatikainen T. Twin pregnancy with a fetus in each half of a uterus didelphys. Acta Obstet Gynecol Scand. 1991;70:373-4.

12. Heinonen PK. Uterus didelphys: a report of 26 cases. Eur $J$ Obstet Gynecol Reprod Biol. 1984; 17:345-50.

13. Skentou C, Souka AP, To MS, Liao AW, Nicolaides KH. Prediction of preterm delivery in twins by cervical assessment at 23 weeks. Ultrasound Obstet Gynecol. 2001;17:7-10.

14. Cahen-Peretz A, Sheiner E, Friger M, Walfisch A. The association between Müllerian anomalies and perinatal outcome. $J$ Matern Fetal Neonatal Med. 2019;32:51-57. 